\title{
UMUR DAN PARITAS IBU BERHUBUNGAN DENGAN ANEMIA PADA IBU HAMIL DI KLINIK BERSALIN SUMIARIANI KEC.MEDAN JOHOR TAHUN 2016
}

\author{
Evi Desfauza \\ Jurusan Kebidanan Medan
}

\begin{abstract}
Abstrak
Sejak 2007, Indonesia tercatat sebagai negara dengan angka kematian ibu (AKI) tertinggi di Asia Tenggara (UNFPA, 2013) dengan 228 kematian per 100.000 kelahiran hidup. SDKI (2013) menunjukkan AKI di Indonesia 359 per 100.000 kelahiran hidup. masih jauh dari target kelima MDG's, 2015 yaitu 102 per 100.000 kelahiran hidup. Di Sumut adanya penurunan AKI akhir 2013 jumlah kematian 249 orang dan 274 ibu meningggal pada tahun 2012. Penyebab langsung kematian ibu adalah perdarahan (39\%), keracunan kehamilan (20\%), infeksi (7\%) dan lain-lain (33\%). Penelitian ini bertujuan untuk mengetahui factor-faktor yang berhubungan dengan terjadinya anemia pada ibu hamil. Populasi adalah seluruh ibu hamil yang datang memeriksakan kehamilannya, dan pengambilan sampel dilakukan secara accidental sampling dari tanggal 17 juni 2016 s/d 30 juni 2016 sebanyak 138 orang.Penelitian ini bersifat analitik dengan metode pendekatan cross sectional. Analisa data secara univariat dan bivariat. yang diuji dengan Chi-Square test. Hasil penelitian menunjukkan adanya hubungan signifikan antara umur dengan anemia pada ibu hamil $p 0,01(<0,05)$, paritas dengan anemia pada ibu hamil dengan $p$ 0,002 $(<0,05)$, dan tidak ada hubungan signifikan antara jarak kelahiran dengan anemia pada ibu hamil. Adanya hubungan umur 20-35 tahun dan paritas $>2$ dengan anemia, sehingga diharapkan kepada tenaga kesehatan untuk meningkatkan penyuluhan dan promosi kesehatan khususnya mengenai keluarga berencana dan nutrisi untuk ibu hamil..
\end{abstract}

Kata Kunci:

\section{A. Pendahuluan}

Badan dunia, United Nation Development Program, Senin (14/12) meluncurkan kajian Human Development Report 2015. Dalam indikator maternal mortality (kematian ibu melahirkan) Indonesia berada pada posisi 190 (kematian) per 100.000 (kelahiran). Pemerintah melalui Survei Demografi dan Kesehatan Indonesia (SDKI) 2012 menyebut angka AKI di Indonesia masih 359 per 100 ribu kelahiran. (Kemenkes 2015)

Sejak 2007, Indonesia tercatat sebagai negara dengan angka kematian ibu (AKI) tertinggi di Asia Tenggara (UNFPA, 2013) dengan 228 kematian per 100.000 kelahiran hidup. Lima tahun kemudian, Survei Demografi dan Kesehatan Indonesia (2013) menunjukkan AKI di Indonesia berada pada angka 359 kematian per 100.000 kelahiran hidup. Angka tersebut tentu masih sangat jauh dari target kelima Millenium Development Goals, yaitu pada 2015 mencapai 102 kematian per 100.000 kelahiran hidup(Kemenkes 2015).

Banyak Negara tidak bisa mencapai sasaran yang ditetapkan dalam Millenium Development Goals (MDGs) seperti halnya Indonesia. Hal ini karena kurangnya pelibatan semua pihak yang berkaitan dengan pembangunan, khususnya pelibatan masyarakat sipil yang merasakan permasalahan yang ada serta mengetahui kebutuhan paling signifikan untuk dipenuhi. Banyak Negara yang tidak bisa mencapai sasaran yang ditetapkan dalam Millenium Development Goals (MDGs). (Kemenkes 2015)

AKI sebesar 359 ini, 82 persennya terjadi pada persalinan ibu berusia muda, 14-20 tahun. Ada berbagai penyebab kematian ibu. Menurut laporan rutin Pemantauan Wilayah Setempat (PWS) tahun 2007, penyebab langsung kematian ibu adalah perdarahan (39\%), keracunan kehamilan (20\%), infeksi (7\%) dan lain-lain (33\%). Kondisi tersebut ditunjang pula dengan keadaan sosial ekonomi sebagian masyarakat yang masih berada digaris kemiskinan, fasilitas kesehatan dan tenaga kesehatan yang belum tersebar secara merata tenaga kesehatan di seluruh wilayah Indonesia(Kemekes 2015)

Menurut Surya Chandra Surapaty tak menampik belum berhasilnya Indonesia menekan AKI. Terdapat empat persoalan menjadi penyebab tingginya AKI. Hal tersebut mencakup hamil terlalu muda dalam usia kurang dari 20 tahun, terlalu tua dalam usia lebih dari 35 tahun, terlalu rapat dengan jarak kehamilan kurang dari tiga tahun, dan terlalu sering dengan anak lebih dari dua.(BKKBN, 2014)

Selain empat persoalan terlalu tersebut, masih ada tiga terlambat yang menyebabkan AKI masih 
tinggi. Hal tersebut mencakup terlambat mengenal tanda bahaya, ambil keputusan, dan menuju fasilitas kesehatan. Faktr medis tak menjadi penyebab tunggal dalan empat terlalu dan tiga terlambat. Hal tersebut juga mencakup pembangunan infrastruktur yang memudahkan akses masyarakat menuju fasilitas kesehatan. (BKKBN, 2014)

Angka kematian ibu hamil maupun melahirkan di Sumut mengalami tren penurunan. Pada akhir 2013 jumlah kematian mencapai 249 orang dan 274 ibu meningggal pada tahun 2012. Menurut Surjantini (2014) Dalam rangka pemenuhan capaian Program Millenium Development Goals (MDG's) 2015. : tercatat hingga Oktober 2014, sebanyak 152 orang dri 206.990 bayi yang lahir hidup di Sumut dari 33 Kabupaten /kota Kabupaten Asahan menjadi penyumbang terbanyak angka kematian ibu, yakni 14 orang,"Selain Asahan, Langkat dan Madina menjadi penyumbang angka kematian ibu terbanyak tahun ini. Sementara Medan, hanya 6 orang dari jumlah itu, berdasarkan hasil survey, penyebab terbesar kematian ibu karena pendarahan sebanyak 50 orang, eklampsia 43 orang, lain-lain 41 orang, infeksi 10 orang, partus macet 5 orang dan abortus 3 orang.(Dinkes Sumut, 2014)

WHO melaporkan bahwa prevalensi ibu-ibu hamil yang mengalami defisiensi besi sekitar 35-75\%, serta semakin meningkat seiring dengan pertambahan usia kehamilan (Rukiyah, A, Y. 2010). Anemia defisiensi zat besi lebih cenderung berlangsung di negara yang sedang berkembang sekitar $52 \%$ sedangkan di negara yang sudah maju sekitar $23 \%$ (Wylie, L. 2008).

Anemia pada ibu hamil merupakan masalah kesehatan terkait dengan insiden yang tinggi dan komplikasi yang dapat timbul baik pada ibu maupun pada janin. Di dunia $34 \%$ ibu hamil dengan anemia dimana $75 \%$ berada di negara sedang berkembang (WHO, 2005 dalam Syafa, 2010). Di Indonesia, 63,5\% ibu hamil dengan anemia (Saifudin. 2006), di Bali 46, 2 $\%$ ibu hamil dengan anemia (Ani, dkk. 2007), dan di RSUD Wangaya Kota Denpasar 25, $6 \%$ ibu hamil aterm dengan anemia (CM RSUD Wangaya. 2010).

Berdasarkan survei awal yang dilakukan penulis di Klinik Bersalin Sumiariani pada bulan Februari tahun 2016 terdapat $79 \mathrm{ibu}$ yang menderita anemia dari $138 \mathrm{ibu}$ hamil. Dari masalah tersebut penulis tertarik mengetahui lebih lanjut tentang "Faktor - faktor yang berhubungan dengan anemia pada ibu hamil di Klinik Bersalin Sumiariani Kecamatan Medan Johor.

\section{B. Metode}

Penelitian ini dilakukan di Klinik Bersalin Sumiariani yang beralamat jalan Karya Kasih X no.69 Medan Johor dari bulan Februari sampai dengan Juli 2016

penelitian ini bersifat survei analitik dengan metode cross sectional sebagai variable independent adalah umur, paritas, dan jarak kehamilan. Sedangkan variabel dependent adalah anemia pada ibu hamil.

Penelitian ini menggunakan data primer yang diperoleh dengan melakukan pemeriksaan kadar hemoglobin dengan menggunakan $\mathrm{Hb}$ sahli dan dummy tabel

Populasi adalah seluruh ibu hamil yang memeriksakan kehamilannya ke Klinik Bersalin Sumiariani pada bulan Mei s/d Juni 2016 sebanyak 138 orang, semua populasi diteliti atau total samping .

Analisis data dilakukan secara Analisis Univariat, Analisis Bivariat

\section{Hasil}

\section{C.1 Analisis Univariat}

Tabel 1. Distribusi Karakteristik Ibu Hamil di Klinik Bersalin Sumiariani Kec Medan Johor Tahun 2016

\begin{tabular}{llc}
\hline \multirow{2}{*}{ No Karakteristik Responden } & \multicolumn{2}{c}{ Jumlah } \\
& F & $\%$ \\
\hline Umur & 31 & 22 \\
$\quad<20->35$ Tahun & 107 & 78 \\
20-35 Tahun & & \\
Paritas & 45 & 33 \\
$>2$ & 93 & 67 \\
$<2$ & & \\
Jarak kelahiran & 111 & 80 \\
$\quad<2$ tahun & 27 & 20 \\
$\quad>2$ tahun & 138 \\
\hline Jumlah & \\
\hline
\end{tabular}

Dari tabel 1. dapat dilihat umur responden mayoritas 20-35 tahun sebanyak 107 orang (78\%), paritas mayoritas < 2 sebanyak 93 Responden (67\%) dan Jarak kelahiran Mayoritas < 2 tahun sebanyak 111 responen $(80 \%)$

\section{C.2. Analisis Bivariat}

Tabel 2. Hubungan Umur Ibu Terhadap Kejadian Anemia di Klinik Bersalin Sumiariani Kec. Medan Johor Tahun 2016

\begin{tabular}{|c|c|c|c|c|c|c|}
\hline \multirow{3}{*}{$\begin{array}{l}\text { Umur } \\
\text { Ibu (th) }\end{array}$} & \multicolumn{4}{|c|}{ Kejadian Anemia } & \multirow{3}{*}{$\boldsymbol{P}$} & \multirow{3}{*}{$\begin{array}{c}\text { PR } \\
(95 \% \\
\text { CI })\end{array}$} \\
\hline & \multicolumn{2}{|c|}{ Anemia } & \multicolumn{2}{|c|}{$\begin{array}{c}\text { Tidak } \\
\text { Anemia }\end{array}$} & & \\
\hline & $\mathbf{N}$ & $\%$ & $\mathbf{N}$ & $\%$ & & \\
\hline$<20 />35$ & 24 & 77,4 & 7 & 22,6 & 0,01 & 1.51 \\
\hline $20-35$ & 55 & 51,4 & 52 & 48,6 & & \\
\hline Total & 79 & 57,2 & 59 & 42,8 & & \\
\hline
\end{tabular}

Berdasarkan hasil penelitian diketahui bahwa ibu hamil yang paling sedikit mengalami anemia yaitu ibu hamil berumur $<20$ dan $>35$ tahun yaitu 24 orang $(77,4 \%)$. dan ibu hamil paling banyak mengalami anemia yaitu ibu hamil berumur 20 - 35 tahun yaitu 55 orang $(51,4 \%)$

Hasil analisa dengan uji Chi - Square $\left(X^{2}\right)$. Didapat nilai $x^{2} \quad 6,648$. Dengan nilai $\mathrm{P},, 010$ berarti nilai $\mathrm{p}$ value $<0,05$. Ini menunujukkan adanya hubungan yang bermakna antara umur ibu hamil $<20$ tahun $>$ lebih dari 35 tahun dengan kejadian Anemia pada ibu hamil. Adapun besarnya beda dapat dilihat dari nilai PR sebesar 1.51 artinya umur ibu hamil $<20$ tahun dan lebih 35 tahun akan 
menimbulkan anemia pada ibu hamil 1,51 kali dibandingkan ibu hamil usia 20 tahun -35 tahun. Umur merupakan salah satu faktor yang menyebabkan terjadinya anemia pada ibu hamil.

Penelitian ini tidak sejalan dengan penelitian Rizqi Ariyani judul penelitianya Faktor-Faktor yang Mempengaruhi Kejadian Anemia Pada Ibu Hamil Trimester III Di Wilayah Kerja Puskesmas Mojolaban Kabupaten Sukoharjo yaitu tidak terdapat hubungan antara umur ibu dengan kejadian anemia $(p=3,555)$,

Penelitian ini sesuai dengan teori yang di kemukakan (Labib, A, T. 2012) hamil diumur yang sangat muda $<20$ tahun atau terlalu tua $>35$ tahun akan mengganggu reproduksi yang mencakup gizi untuk menjamin pertumbuhan sempurna. Kehamilan diusia $<20$ tahun dan diatas 35 tahun dapat menyebabkan anemia karena pada kehamilan diusia $<20$ tahun secara biologis belum optimal emosinya cenderung labil, mentalnya belum matang sehingga mudah mengalami keguncangan yang mengakibatkan kurangnya perhatian terhadap pemenuhan kebutuhan zat - zat gizi selama kehamilannya. Sedangkan pada usia > 35 tahun terkait dengan kemunduran dan penurunan daya tahan tubuh serta berbagai penyakit yang sering menimpa diusia ini. Dengan demikian dari hasil penelitian ini tidak ditemukan kesenjangan antara hasil penelitian dan teori.

Tabel 3. Hubungan Paritas Ibu Terhadap Kejadian Anemia di Klinik Bersalin Sumiariani tahun 2013

\begin{tabular}{ccccccc}
\hline & \multicolumn{3}{c}{ Kejadian Anemia } & & PR \\
\cline { 2 - 5 } Paritas & Anemia & \multicolumn{2}{c}{ Tidak } & & P \\
& & \multicolumn{95}{c}{ Anemia } \\
& $\mathbf{N}$ & $\mathbf{\%}$ & $\mathbf{N}$ & $\mathbf{\%}$ & & CI) \\
\hline$>2$ & 34 & 75,6 & 11 & 24,4 & 0,002 & 1.561 \\
$\leq 2$ & 45 & 48,4 & 48 & 51,6 & & \\
\hline Total & $\mathbf{7 9}$ & $\mathbf{5 7 , 2}$ & $\mathbf{5 9}$ & $\mathbf{4 2 , 7}$ & & \\
\hline $\mathrm{X} 2=9,146$ & & & & & &
\end{tabular}

Berdasarkan hasil penelitian diketahui bahwa ibu hamil dengan paritas $>2$ lebih banyak mengalami anemia yaitu 34 orang $(75,6 \%)$ dan ibu hamil $\leq 2$ yang mengalami anemia paling banyak yaitu orang 45 orang $(48,4 \%)$.

Hasil analisa dengan uji Chi - Square $\left(X^{2}\right)$ didapat nilai $X^{2}=9,138$. dengan $P=0,002(<0,05)$ memperlihatkan adanya hubungan paritas ibu dengan terjadinya anemia pada ibu hamil. Didapat nilai $\mathrm{PR}=1.561$ yang artinya paritas >2 akan menimbulkan kejadian anaemia pada ibu hamil 1,561 kali lebih tinggi dibandingkan ibu hamil paritas $\leq 2$

Penelitian ini sejalan dengan hasil penelitian Nesi Novita di Puskesmas Babat Toman Kabupaten Musi Banyuasin yang menyatakan adanya hubungan paritas dengan kejadian anemia pada ibu hamil ( $\mathrm{P}$ value $=0,001$ $(<=0,005)$. Hal tersebut sesuai juga dengan teori yang dikemukakan oleh (Labib,A,T.2012). semakin sering wanita menjalani kehamilan dan melahirkan akan semakin banyak kehilangan zat besi dan akan menjadi semakin anemia. Jika persediaan cadangan zat besi minimal maka setiap kehamilan dan persalinan akan menguras cadangan
Fe pada tubuh dan akhirnya menimbulkan anemia pada kehamilannya berikut.

Tabel 2.3 Hubungan Jarak Kelahiran dengan Kejadian Anemia di Klinik Bersalin Sumiariani Tahun 2013

\begin{tabular}{|c|c|c|c|c|c|c|}
\hline \multirow{3}{*}{$\begin{array}{c}\text { Jarak } \\
\text { kelahiran }\end{array}$} & \multicolumn{4}{|c|}{ Kejadian Anemia } & \multirow{3}{*}{$P$} & \multirow{3}{*}{$\begin{array}{c}\text { PR } \\
(95 \% \mathrm{CI})\end{array}$} \\
\hline & \multicolumn{2}{|c|}{ Anemia } & \multicolumn{2}{|c|}{$\begin{array}{c}\text { Tidak } \\
\text { Anemia }\end{array}$} & & \\
\hline & $\mathbf{N}$ & $\%$ & $\mathbf{N}$ & $\%$ & & \\
\hline$<2$ & 68 & 61,3 & 43 & 38,7 & 0,053 & 1.503 \\
\hline$\geq 2$ & 11 & 40,7 & 16 & 59,3 & & \\
\hline Total & 79 & 57,2 & 59 & 50 & & \\
\hline
\end{tabular}

Berdasarkan hasil penelitian diketahui bahwa ibu hamil dengan jarak kehamilan $<2$ tahun mayoritas mengalami anemia sebanyak 68 orang $(61,3 \%)$, sedangan Ibu hamil jarak kehamilan $\geq 2$ mengalami anemia yaitu orang 11 orang $(40,7 \%)$.

Hasil analisis bivariat dengan uji Chi - Square didapat nilai $\chi^{2}=3,735$ dengan P.0,053 $(>0,05)$ memperlihatkan tidak adanya hubungan jarak kelahiran dengan terjadinya anemia pada ibu hamil

Penelitian ini tidak sejalan dengan penelitian Rohmah Dyah Nurhidayat yang berjudul Analisis Faktor Penyebab Terjadinya Anemia Pada Ibu Hamil Di Wilayah Kerja Puskesmas Tawangsari Kabupaten Sukoharjo yang menyatakan terdapat hubungan bermakna jarak kehamilan dengan kejadian anemia pada ibu hamil,

Jarak kelahiran yang pendek mengakibatkan fungsi alat reproduksi masih belum optimal. Pengaturan jarak kelahiran yang baik minimal dua tahun menjadi penting untuk diperhatikan sehingga badan ibu siap untuk menerima janin kembali tanpa harus menghabiskan cadangan zat besinya (Labib, A, T. 2012).

\section{Simpulan}

Berdasarkan hasil penelitian mengenai Faktor - faktor yang berhubungan dengan anemia pada ibu hamil di Klinik Bersalin Sumiariani Kec.Medan Johor tahun 2016 dapat diambil kesimpulan sebagai berikut :

a. Jumlah ibu hamil yang mengalami anemia di Klinik bersalin Sumiariani Kec.Medan Johor pada bulan februari tahun 2016 sebanyak 79 orang dari 138 ibu hamil.

b. Ada hubungan umur ibu dengan terjadinya anemia pada ibu hamil.

c. Ada hubungan paritas dengan terjadinya anemia pada ibu hamil.

d. Tidak ada hubungan jarak kelahiran dengan terjadinya anemia pada ibu hamil.

\section{Saran}

Adapun saran yang dapat penulis sampaikan pada penelitian ini adalah sebagai berikut :

a. Disarankan kepada setiap tenaga kesehatan khususnya petugas kesehatan di Klinik Bersalin Sumiariani untuk selalu memberi penyuluhan caracara pencegahan anemia pada ibu hamil dan 
memotivasi ibu agar bersedia mengikuti program keluarga berencana

b. Bagi Instusi pendidikan, agar dalam masa pendidikan D-III dan D-IV Kebidanan., teori tentang deteksi dini dan pencegahan anemia pada ibu hamil selalu ditekankan, sehingga setelah lulus dapat memberikan pelayanan kepada masyarakat pada saat melaksanakan praktek bidan mandiri

\section{Daftar Pustaka}

Hasibuan, Y, 2011, Diktat Biostatistika, Politeknik Kesehatan, Medan.

http://id.wikipedia.org/wiki/Tujuan_Pembangunan_Mil enium gandeng-ibi-dan-idi-demi-capai-targetmdgs-2015

http://www.jdih.net/web_bppkb/berita/269/bkkbn-

Karunia, 2011. Faktor-faktor yang Berhubungan Dengan Kejadian Anemia Pada Ibu Hamil, Diakses 28 Februari 2013 Pukul 10. 15 wib:

http://kti-kebidanan-gratis.blogspot.com.

Kementerian Kesehatan RI. 2013. Riset Kesehatan Dasar, Riskesdas 2013. Kementerian Kesehatan RI, Jakarta.

Kementerian Kesehatan RI. 2014. Profil Kesehatan Indonesia Tahun 2013. Kementerian Kesehatan RI, Jakarta.

Kusumawardani, E, 2010, Waspada Penyakit Darah Mengintai Anda, Hanggar Kreator, Yogyakarta.

Labib, A, T, 2012, Larangan-Larangan Yang Tidak Boleh Dilakukan Oleh Ibu Hamil, Cable Book, Jakarta.

Notoatmodjo, S, 2011, Kesehatan Masyarakat Ilmu Dan Seni, PT Asdi Mahasatya, Jakarta.
Prawirohardjo, S, 2008, Imu Kebidanan Edisi Keempat, PT Bina Pustaka, Jakarta.

Proverawati, A, 2009, Buku Ajar Gizi Untuk Kebidanan, Numes, Yogyakarta.

Proverawati, A, 2011, Anemia Dan Anemia Kehamilan, Numes, Yogyakarta.

Rizqi Ariyani, 2013 : Jurnal Faktor-Faktor Yang Mempengaruhi Kejadian Anemia Pada Ibu Hamil Trimester Iii Di Wilayah Kerja Puskesmas Mojolaban Kabupaten Sukoharjo

Rohmah, 2013 Jurnal Analisis Faktor Penyebab Terjadinya Anemia Pada Ibu Hamil Di Wilayah Kerja Puskesmas Tawangsari Kabupaten Sukoharjo

Rukiyah, A, Y, 2010, Asuhan Kebidanan IV Patologi, Trans Info Media, Jakarta.

Selengkapnya :

http://www.kompasiana.com/ditaanugrah/angkakematian-ibu-di-indonesia-masih-jauh-daritarget-mdgs-2015 54f940b8a33311ba078b4928

Tarwoto, 2007. Buku Saku Anemia Pada Ibu Hamil, Trans Info Media, Jakarta.

Waryana, 2010, Gizi Reproduksi, Pustaka Rihana, Jogyakarta.

Wylie, L, 2011, Manajemen Kebidanan Gangguan Medis Kehamilan Dan Persalinan, EGC, Jakarta. 